\title{
EDITORIAL
}

\section{The thaw beneath our feet}

\author{
Permafrost is thawing as global temperatures rise. This Issue focuses on the changing status of \\ permafrost and its broader impacts.
}

Permafrost - ground that remains $\leq 0^{\circ} \mathrm{C}$ for at least two consecutive years - is thawing. The resulting impacts are vast and potentially rapid, influencing both human and natural systems. For instance, 10 s to 100 s Pg of carbon could be released by the end of this century (with even greater losses after 2100), driving the permafrost carbon feedback that contributes further warming. Moreover, one third of Arctic infrastructure faces high risk thaw-related structural damage by mid-century, and high-latitude coastal infrastructure is threatened by rapidly increasing erosion.

Since these potential impacts were first recognized, the research community has risen to the challenge of documenting permafrost and predicting changes. Accordingly, there is now clear evidence that anthropogenic warming has led to permafrost warming, high confidence that thawing permafrost will release carbon, and new recognition of previously underappreciated processes such as wintertime carbon losses and $\mathrm{N}_{2} \mathrm{O}$ emissions. In this Issue, and an accompanying online Collection, we take stock of these developments and document the multifaceted understanding of permafrost.

Permafrost is frozen ground, so it stands to reason that with rising global temperatures, this ground will thaw. Such physical changes are already apparent. As reported by Smith et al., the highest recorded permafrost temperatures in northern regions were observed in 2018-2019, and in cold continuous permafrost, warming of up to $1{ }^{\circ} \mathrm{C}$ per decade is documented. As permafrost warms and thaws, the overlying active layer thickens and the regional hydrology changes. Ground subsidence causes the formation of thermokarst lakes that degrade the permafrost underneath them. However, these lakes also tend to drain, promoting permafrost aggradation and ground ice formation under the right climate conditions. As Jones et al. explain, it is difficult to predict future lake formation and drainage dynamics, but warming temperatures will likely slow new permafrost formation.

Thermokarst lakes not only impact regional hydrology and permafrost, but also carbon cycling. Miner et al. outline how the emergence of abrupt permafrost thaw stands to disproportionally increase carbon emissions from the Arctic, adding to the billions of tonnes of carbon expected to be released through gradual permafrost thaw by 2100 . However, as pointed out by Heijmans et al., $20-40 \%$ of the Arctic tundra has exhibited

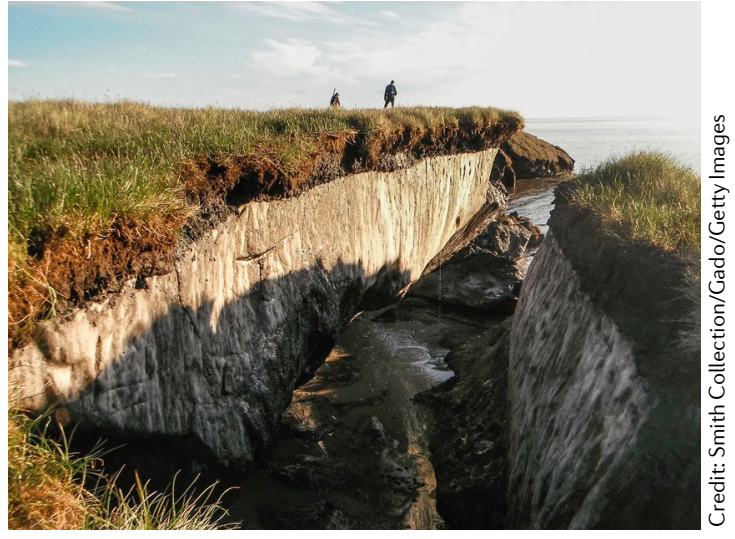

spectral greening since the 1980s, a trend supported by on-the-ground observations of shrub cover increases. This greening could potentially mitigate some of the thaw-related carbon emissions, although both sides of this carbon tug-of-war are threatened by the increasing risk of wildfires.

Although carbon release from permafrost tends to dominate headlines, the societal impacts of permafrost thaw, particularly the very real impacts on Northern Communities, cannot be ignored. Irrgang et al. explain how ecosystem services and hunting grounds that support subsistence-based lifestyles, heritage sites and communities are threatened by thaw-related coastal erosion. Rapid changes in lakes and drained basins further challenge animal husbandry, such as reindeer herding, and threaten water supplies. Furthermore, permafrost degradation will impact key infrastructure, with maintenance costs on the order of billions of dollars in the upcoming decades, articulated in Hjort et al.

There is work left to do. Indeed, while progress in understanding permafrost and its role in the Earth system has clearly improved, all articles in this Issue outline vast uncertainties and continued unknowns. Better representation of permafrost in models and reduced geographical biases in data collection offer some potential. However, cooperation and collaboration - between researchers and Indigenous communities, between fields and between regions - are key to advancement. As noted by Oleg Anisimov in describing Western-Russian collaborations, it is imperative that communities from across the world work together to share data and ideas to enhance understanding of the permafrost thaw under our feet. 